\title{
CUTANEOUS WOUND HEALING: CORRELATION BETWEEN EPIDERMAL PROLIFERATING CELL NUCLEAR ANTIGEN AND DESMOPLAKIN EXPRESSION.
}

\author{
By \\ Rania N. Sherif and Mohamed Y. Breika
}

\author{
From \\ Anatomy and Embryology Department, Faculty \\ of Medicine Mansoura University
}

\begin{abstract}
Introduction \& Aim of the work :

Resurfacing a wound with new epithelium involves two important processes, proliferation and migration of keratinocytes. This study aimed to investigate the correlation between epidermal proliferating cell nuclear antigen and desmoplakin expressions during normal wound healing in mice.
\end{abstract}

\section{Material and methods :}

Thirty male albino mice were divided randomly into 2 groups, control $(n=6)$ left unwounded, and wound model group $(n=24)$. Two fullthickness linear wounds $(2 \mathrm{~cm})$ were made on the shaved dorsum of the wound model group. At different time periods $(1,2,4,6$ days) after wound, skin specimens including samples from the wounds were excised, processed as paraffin blocks, sectioned and immunostained with anti-PCNA and anti-desmoplakin (11-5F) antibodies.

\section{Results :}

During early process of wound healing, the cells at the margin of the wound proliferated and were pushed toward the surface in-order to migrate as evidenced by absence of desmoplakin expression. Later, at wound margin desmoplakin expression reappeared and proliferation of cells decreased. The new epidermis in the floor of the wound formed the source of the cells that would cover the wound. The keratinocytes in the floor 


\section{CUTANEOUS WOUND HEALING: CORRELATION BETWEEN etc.}

of the wound proliferated to supply the migrating and differentiating cells, after which they normalized their proliferation rate and restored their desmoplakin expression in the peripheral areas.

\section{Conclusion :}

Early during wound healing, the cells at the wound margin form the primary source of the cells that would cover the wound. Later, the new epidermis in the floor of the wound would form this source.

Keywords : wound healing, PCNA, desmoplakin.

Corresponding Author : Rania Naiem Sherif

\section{INTRODUCTION}

Skin wound healing represents a dynamic and well ordered biological process (Clark, 1996 and Martin, 1997). The sequence of events in wound healing in skin has been intensively studied (Li et al., 2007).

Re-epithelialization is resurfacing a wound with new epithelium to restore the full thickness of the epidermis. It involves two important proVol. 40, No. 1 \& 2 Jan., \& April, 2009 cesses, proliferation and migration of keratinocytes (Li et al., 2007 and Javierre et al., 2009). Cell proliferation is an essential event during reepithelization. Proliferating cell nuclear antigen (PCNA) has been considered as a well-known marker of cell proliferation (Brabo and MacdonaldBrabo, 1987).

Proliferating keratinocytes ensure an adequate supply of cells to migrate into and cover the wound (Li et al., 2007) then cellular migration plays a very important role in restoring epidermal continuity (Stenn and Malhotra 1992).

Desmosomes are the principal junctions of epidermal cells and are essential for the normal integrity and barrier function of unwounded adult skin (Vasioukhin et al., 2001 \& Jonkman et al., 2005). Migrating keratinocytes undergo subcellular modifications including disassembly of hemidesmosomal links between epidermis and dissolution of most desmosomes (Singer and Clark, 1999).

The desmosomal junction comprises numerous proteins from at 
least three different families: the cadherins, the armadillo proteins, and the plakins (Getsios et al., 2004). Desmoplakin is an important component of desmosomes structures that mediate intercellular adhesion in tissues subjected to mechanical stress and that serve as anchoring sites for the intermediate filament (IF) system (Getsios et al., 2004). Desmoplakin (DSP) is present in all desmosomal junctions (North et al., 1999) and exists as two isoforms, DSPI and DSPII (Green et al., 1990 and 1992).

To date, there is no study that has simultaneously investigated both proliferation and desmoplakin expression in the epidermal cells during the normal process of wound healing. The present study aimed to investigate the correlation between epidermal PCNA expression as marker for the prolifertaive state and desmoplakins expression as marker for desmosomal distribution during normal wound healing in mice.

\section{MATERIAL \& METHODS}

Animals

Thirty male albino mice, 812 weeks of age, weighting $20-22 \mathrm{~g}$ were obtained from experimental research center of Theodor Bilharz Institute, Cairo, Egypt. The animals had free access to water and food add libitum and were maintained in a room with controlled humidity and temperature $\left(25^{\circ} \mathrm{C} \pm 2\right)$ with12 $\mathrm{h} / 12 \mathrm{~h}$ light/ dark cycle. All experiments were performed in accordance with the protocol approved by the committee on animals' experimentation of Mansoura University.

\section{Cutaneous wound model}

A model of cutaneous wound was made on the shaved backs of the animals. Under anesthesia with phentobarbital $(60 \mathrm{mg} / \mathrm{kg}$ ) administered intraperitoneally, two full-thickness linear wounds $(2 \mathrm{~cm})$ were made on the dorsum of the mice by incising the skin to the level of the subcutaneous muscle panniculus carnosus with a sterile scalpel (Tomlinson and Ferguson, 2003). Wounds were left not sutured or covered and left to heal by secondary intension. The animals were harvested at different time points (1, 2, 4 and 6days) after incision (six mice at each time point). Six mice were left unwounded and were used as control group.

MANSOURA MEDICAL JOURNAL 
246 CUTANEOUS WOUND HEALING: CORRELATION BETWEEN etc..

Skin specimens including samples from the wounds were excised. Paraffin-embedded samples were prepared and cut into sections perpendicular to the skin surface by a microtome set and stained with haematoxylinjeosin for general morphological evaluation.

\section{Immunocytochemical stains :}

Paraffin-embedded $5 \mu \mathrm{m}$ skin sections were mounted on glass slides coated with $0.1 \%$ poly-I-lysine. Sections were heated by microwave oven at $92^{\circ} \mathrm{C}$ for $10 \mathrm{~min}$, and then cooled for $60 \mathrm{~min}$ at room temperature. Endogenous peroxidase activity was inhibited by incubation with $3 \%$ hydrogen peroxidase in methanol for 20 min. Nonspecific reactions were blocked by $10 \%$ normal rabbit serum.

Mouse monoclonal anti-PCNA antibody (DAKO, Milan, Italy) (Fukuda et al., 2002) and monoclonal antibody to desmoplakin (11-5F) (which reacts with both DSPI and DSPII) (Parrish et al., 1987) at dilution 1:200 and 1:50 respectively were used as primary antibodies at $4^{\circ} \mathrm{C}$ overnight. The sections were then incubated with biotinylated rabbit anti-mouse Vol. 40, No. 1 \& 2 Jan., \& April, 2009 immunoglobulin for $\mathbf{3 0} \mathrm{min}$, followed by incubation with streptavidinperoxidase complex for $30 \mathrm{~min}$ and rinsed with phosphate-buffered saline. The color was developed with $D A B$. Finally, they were lightly counterstained with haematoxylin. Sections stained without primary antibodies served as negative controls. Sections of rat prostate were used as positive control for PCNA (Fig. AA) and sections of rat skin were used as positive control for 11-5F (Fig. BB)

\section{Evaluation of PCNA index}

The number of keratinocytes with PCNA-positive nuclei and the total number of keratinocytes were counted by two independent observers (x400 magnification). The proliferation index was calculated by dividing the number of keratinocytes with PCNApositive nuclei by the total number of keratinocytes per section $\times 100 \%$.

\section{Statistical analyses}

All data were reported as mean \pm standard error of mean. PCNA indices were statistically analyzed by Mann-Whitney test using SPSS software. Values of $P<0.05$ were considered statistically significant. 


\section{Rania N. Sherit and Mohamed Y. Breika}

RESULTS

All animals tolerated the wounding procedures without any obvious problems. Two animals developed signs of infection, manifested by purulence.

\section{Control group :}

Haematoxylin and eosin stained sections revealed normal structure of the skin. The epidermis is relatively thin and is formed of 2-3 layers of keratinocytes covered by a thin layer of keratin (Fig. 1).

Sections stained with the PCNA antibody showed positive PCNA immunoreactivity that is confined only to the nuclei of the basal keratinocyte (Fig. 2). PCNA index was $40.46 \% \pm$ 5.27 (Tab.1). Positive PCNA immunoreactivity was also observed in the cells of hair follicles (Fig. 2).

Desmoplakin expression in the uninjured skin sections was observed in the whole thickness of the epidermis. Immunoreactivity has been detected in the form of brown stained lines and granules in-between the keratinocytes of all layers of epidermis (Fig. 3).
One day after the skin injury:

Haematoxylin \& eosin stained sections showed increase in the number of epidermal layers at the wound margins (3-4 layers). The wound surface was covered by blood clot (Fig. 4). PCNA positive keratinocytes were observed mainly in the basal layer of the epidermis at the wound margins with few positive cells in the suprabasal layers (Fig. 5). PCNA index at wound margin was $65.28 \% 2.08$ (Tab. 1) which was highly significant higher than that of the uninjured skin. There was partial loss of desmoplakin expression in-between cells of the superficial layers of the wound margin (Fig. 6).

A tongue of new epidermal cells (epithelial spur) had begun to invade the underlying connective tissue at each side of the wound to cover the raw surface. This tongue process was 2-3 layers thickness and was devoid of superficial keratin layer (Fig. 4). PCNA positive cells were observed in the basal layer and in some cells of the suprabasal layers of the neoepidermis at the floor of the wound with PCNA index $35.50 \% \pm 2.85$ (Fig. 5 and Tab. 2). Desmoplakin reactivity

MANSOURA MEDICAL JOURNAL 


\section{CUTANEOUS WOUND HEALING: CORRELATION BETWEEN etc.}

was only restricted in-between few cells in the basal layer of the neoepidermis (Fig. 6).

Two days after the skin injury:

The epidermal layers at the wound margins were increased (4-5) layers (Fig. 7). PCNA positive keratinocytes were observed mainly in the basal layer of the epidermis at the wound margins (Fig. 8). The number of PCNA positive cells was highly significantly lower than that of the 1st day (index $=41.65 \% \pm 6.4$ ) (Tab. 1). The cells of the wound margin showed disappearance of the desmosoplakin expression in-between the cells of the superficial layers (Fig. 9).

The epithelial tongue increased in length, showed early evidence of keratinization and covered with a blood clot (Fig. 7). PCNA positive cells were observed in the basal and upper layers of the neoepidermis with PCNA index $44.18 \% \pm 7.05$ which was significantly higher than that of the $1^{\text {st }}$ day after injury (Fig. 8 \&Tab. 2). Desmoplakin reactivity was detected inside the cells (intra-cytoplasmic) of the neoepidermis (Fig. 9).

Vol. 40, No. 1 \& 2 Jan., \& April, 2009
Four days after the injury:

The epidermal layers at the wound margin were still hyper-plastic and reached its maximum number (10-12 layers) (Fig. 10). The cells with positive PCNA expression were decreased in number and were coincided to the basal and suprabasal layers of the wound margin with low PCNA index $(41.42 \% \pm 9.90)$ (Fig. 11 \& Tab. 1) which was not significantly different from that of the 2nd day. Positive desmoplakin reactivity reappeared between the keratinocytes of all layers at the wound margin (Fig. 12).

The epithelial tongue increased in length and consisted of multiple layers (3-4 layers) covered with thin layer of keratin in its peripheral part (Fig. 10).

The peripheral part of the neoepidermis close to the wound margin showed high number of PCNA positive cells seen only in basal layer. The PCNA index did not significantly differ from that of the floor of the wound in the $2^{\text {nd }}$ day (Fig. 11). Some positive desmoplakin reactivity was observed in-between the cells of the peripheral part of the neoepidermis (Fig. 12). 
The central part of the neoepidermis close to the wound gap showed PCNA positive cells in basal and suprabasal layers with PCNA index $43.90 \% \pm 13.22$ (Fig. 11 \& Tab. 2). No desmoplakin reactivity was mainly detected inbetween the cells of the central part of the neoepidermis (Fig. 12).

Positive PCNA immunoreactivity increased in the cells of the hair follicles at different stages of wound healing (Fig. 11).

Six days after the injury:

The wound became completely healed and covered with keratinized epithelium formed of 3-4 layers (Fig. 13).

The epithelium at the wound mar- gin was still hyper-plastic (10-12 layers) (Fig. 13). Few PCNA positive cells were detected in the basal layer of the wound margin (Fig. 14) with PCNA index $27.17 \% \pm 2.14$ which was highly significantly lower than that of the $4^{\text {th }}$ day and significantly lower than that of the control (Tab. 1). Positive desmoplakin reactivity was detected between the cells of all layers of the wound margin (Fig. 15).

Few PCNA positive cells were detected in the basal layer of the floor of the wound. The PCNA index was $23.69 \% \pm 1.63$ in the peripheral part and $8.78 \% \pm 1.87$ in the central part (Fig. 14) which was highly significantly lower than those of the 4th day (Tab. 2). Positive desmoplakin reactivity appeared between cells in the floor of the wound (Fig.15). 
250 CUTANEOUS WOUND HEALING: CORRELATION BETWEEN etc.

Table (1): PCNA index of the control group and the wound margin of experimental groups at different intervals $(1,2,4, \& 6$ days after the injury). Values are presented as means $\pm \mathrm{SD}$

\begin{tabular}{|c|c|c|c|c|}
\hline & Mean & $\begin{array}{c}\text { Std. } \\
\text { Deviation }\end{array}$ & $\begin{array}{c}\text { P value } \\
\text { (vs control) }\end{array}$ & $\begin{array}{c}\text { P value } \\
\text { (vs previous } \\
\text { group) }\end{array}$ \\
\hline CONTROL & 40.46 & 5.27 & & \\
\hline 1day after injury & 65.28 & 2.08 & $.000^{* *}$ & .649 \\
\hline 2days after injury & 41.65 & 6.41 & .190 & $.000^{* *}$ \\
\hline 4days after injury & 41.42 & 9.90 & $.002^{*}$ & $.032^{*}$ \\
\hline 6days after injury & 27.17 & 2.14 & & \\
\hline
\end{tabular}

* The mean difference is significant $(P \leq 0.05)$.

** The mean difference is highly significant $(\mathrm{P} \leq 0.001)$.

Table (2): PCNA index of the floor of the wound of experimental groups at different intervals $(1,2,4, \& 6$ days after the injury). Values are presented as means \pm SD

\begin{tabular}{|l|c|c|c|}
\hline & Mean & Std. Deviation & P value \\
\hline 1day after injury & 35.50 & 2.85 & \\
\hline 2days after injury & 44.18 & 7.05 & $.047^{\star}$ \\
\hline 4days after injury (peripheral part) & 44.16 & 10.47 & $.994^{\star *}$ \\
\hline 4days after injury (central part) & 43.90 & 13.22 & \\
\hline 6days after injury (peripheral part) & 23.69 & 1.63 & .003 \\
\hline 6day after injury (central part) & 8.78 & 1.87 & $.000 \star 4$ \\
\hline
\end{tabular}

The mean difference is significant $(\mathrm{P} \leq 0.05)$.

The mean difference is highly significant $(\mathrm{P} \leq 0.001)$.

* D2 floor versus D1 floor (significant).

** D4 floor versus D2 floor.

- D6 floor versus D4 floor (peripheral parts).

$\leftrightarrow$ D6 floor versus D4 floor (central parts).

Vol. 40, No. 1 \& 2 Jan., \& April, 2009 


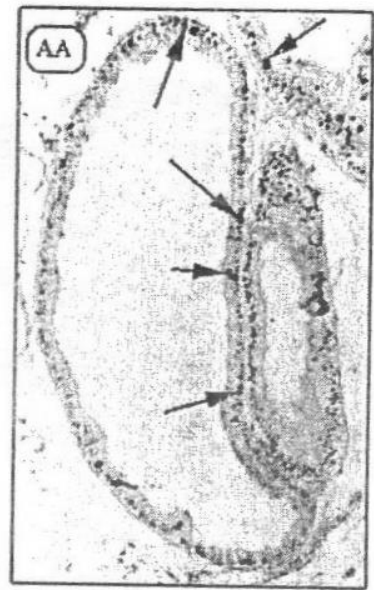

Fig. AA : A photomicrograph of a section of the rat prostate showing positive PCNA immunoreactivity (arrows). PCNA immunoperoxidase stain; $\mathrm{X} 100$

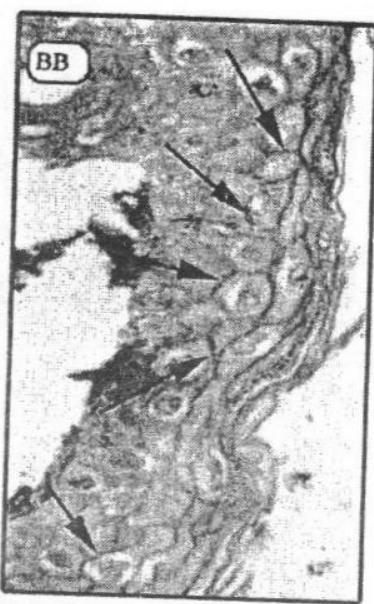

Fig. BB : A photomicrograph of a section of the rat skin showing positive immunoreactivity for desmoplakin (arrows). 11-5F immunoperoxidase stain; $\mathrm{X} 400$

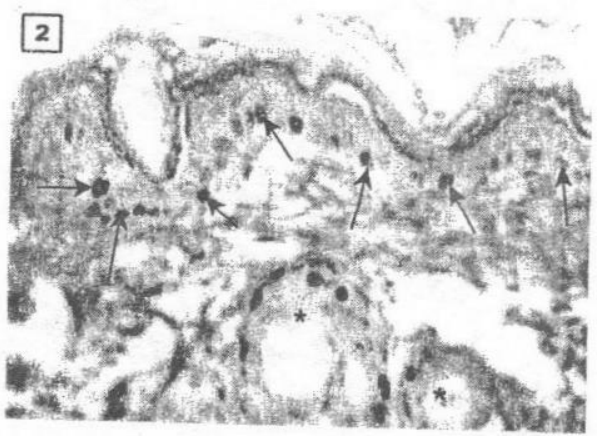

Fig. 2 : A photomicrograph a section of the mice skin of the control group showing positive PCNA immunoreactivity in the nuclei of the basal keratinocyte (arrows) and positive PCNA cells of hair follicles (*). PCNA immunoperoxidase stain; $X 400$ MANSOURA MEDICAL JOURNAL 


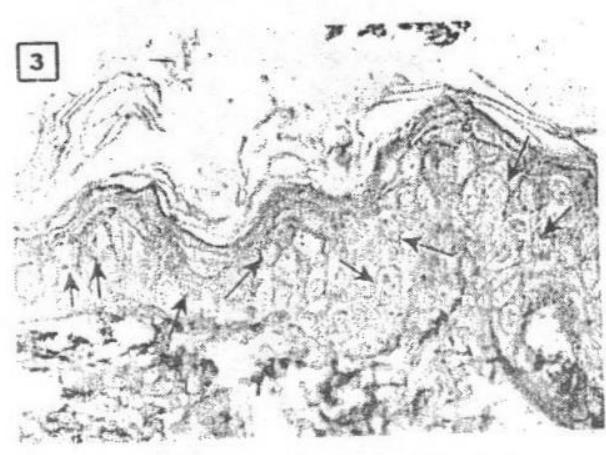

Fig. 3 : A photomicrograph of a section of the mice skin of the control group showing positive immunoreactivity in the form of brown stained lines and granules in-between the keratinocyte in all layers of epidermis (arrows). 11-5f immunoperoxidase stain; X400

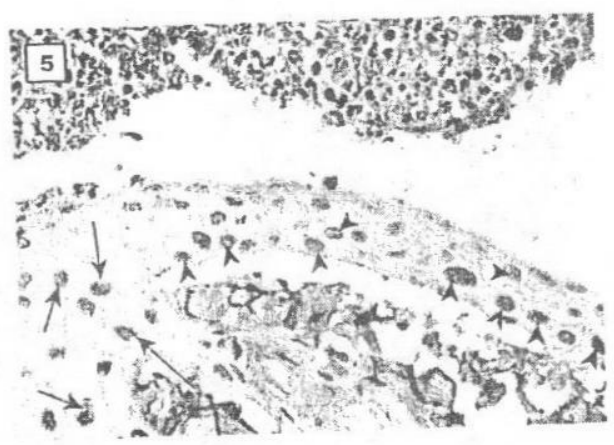

Fig. 5: A photomicrograph a section of the mice skin 1 day after the injury showing PCNA positive keratinocytes in the basal and suprabasal layers at the wound margins (arrows), PCNA positive cells can be seen in the basal layer and few suprabasal layers of the neoepidermis (arrow heads). PCNA immunoperoxidase stain; $X 400$

Vol. 40, No. 1 \& 2 Jan., \& April, 2009

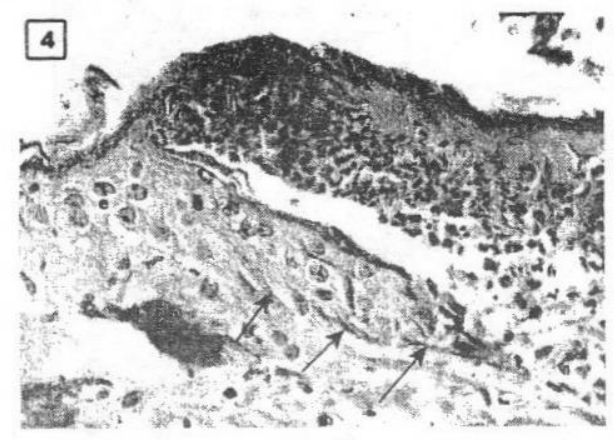

Fig. 4 : A photomicrograph of a section of the mice skin 1day after the injury showing increase in the number of epidermal layers at the wound margins (e), wound surface is covered by blood clot $\left({ }^{*}\right)$, tongue of new epidermal cells (arrows) invade the underlying connective tissue. Hx. \& E.; X400

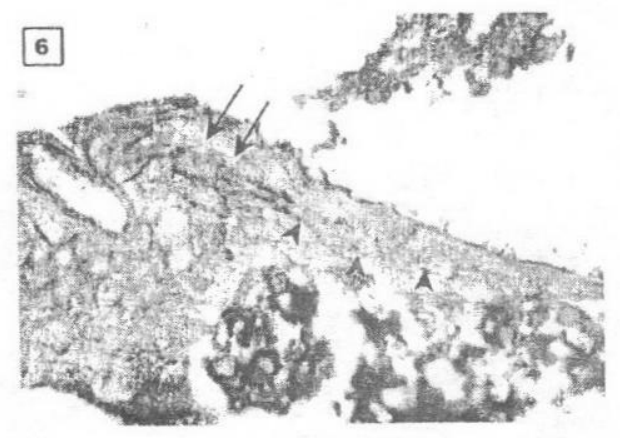

Fig. 6 : A photomicrograph of a section of the mice skin 1 day after the injury showing partial loss of desmoplakin expression in-between cells of the superficial layers of the wound margin (arrows), few desmoplakin reactivity can be seen in-between cells in the basal layer of the neoepidermis (arrow heads). 11-5F immunoperoxidase stain; X400 


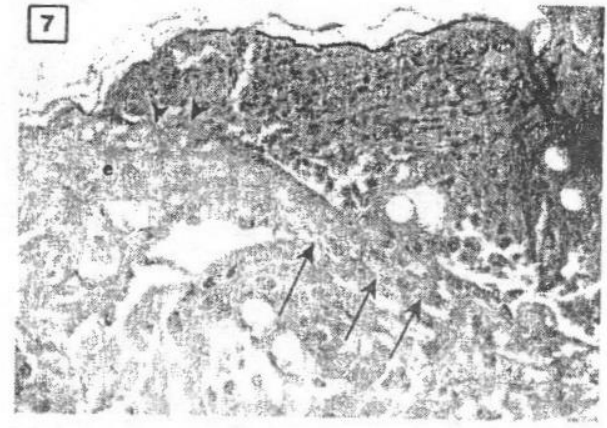

Fig. 7 : A photomicrograph of a section of the mice skin 2days after the injury showing increase number of epidermal layers (e), epithelial tongue increased in length (arrows), with early evidence of keratinization (arrow heads). Hx. \& E.; X400

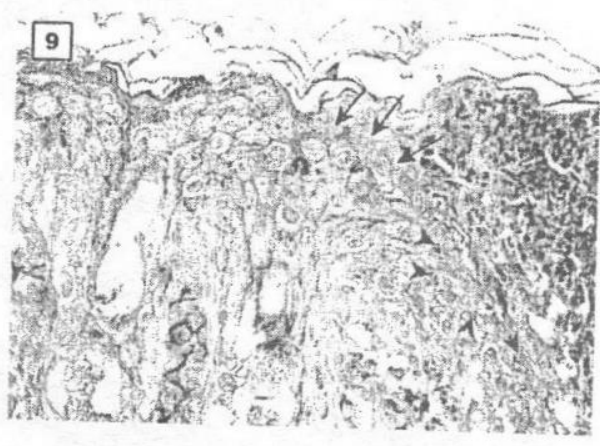

Fig. 9 : A photomicrograph of a section of the mice skin 2 days after the injury showing disappearance of the desmosoplakin expression in-between the cells of the superficial layers (arrows), intra-cytoplasmic desmoplakin reactivity was detected in the cells of the neoepidermis (arrow heads). 11-5F immunoperoxidase stain; $\mathrm{X} 400$

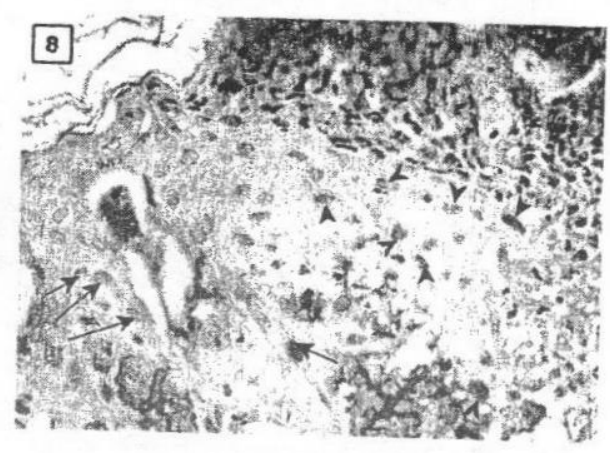

Fig. 8 : A photomicrograph a section of the mice skin 2 days after the injury showing PCNA positive keratinocytes in the basal layer of the epidermis at the wound margins (arrows), PCNA positive cells were observed in the basal and upper layers of the neoepidermis (arrow heads). PCNA immunoperoxidase stain; $\mathrm{X} 400$

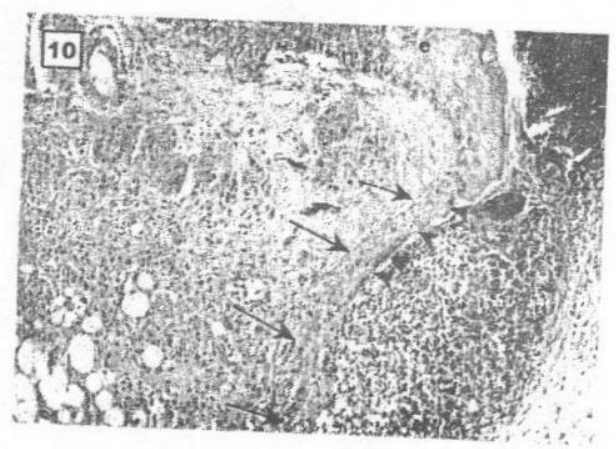

Fig. 10: A photomicrograph of a section of the mice skin 4 days after the injury showing hyperplastic epidermis (e), epithelial tongue consists of multiple layers (arrows) covered with thin layer of keratin in its peripheral part (arrow heads). Hx. \& E.; X400

MANSOURA MEDICAL JOURNAL 
254 CUTANEOUS WOUND HEALING: CORRELATION BETWEEN etc..

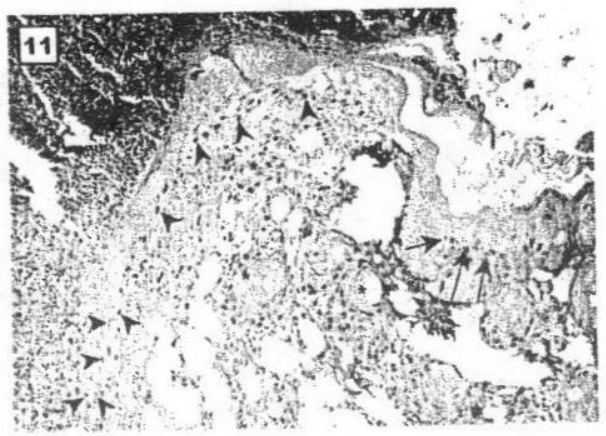

Fig. 11: A photomicrograph a section of the mice skin 4 days after the injury showing few positive PCNA cells in the basal and suprabasal layers (arrows), large number of PCNA positive cells can be seen in the peripheral part (arrow heads) and central part of the neoepidermis (blue arrow heads). PCNA immunoperoxidase stain; X100

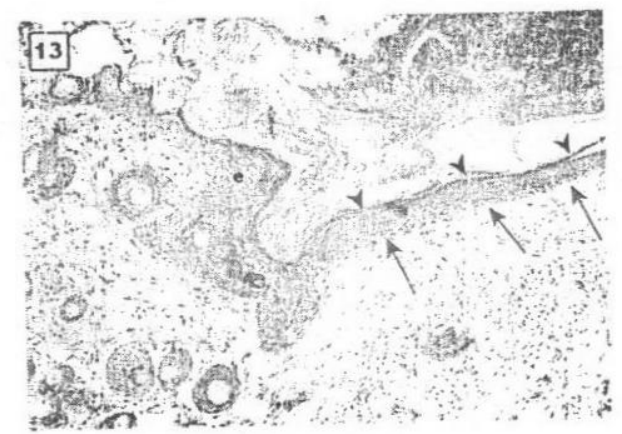

Fig. 13: A photomicrograph of a section of the mice skin 6 days after the injury showing completely healed wound (arrows) and covered with keratin (arrow heads), epithelium at the wound margin is hyper plastic (e). Hx. \& E.; X400

Vol. 40, No. 1 \& 2 Jan., \& April, 2009

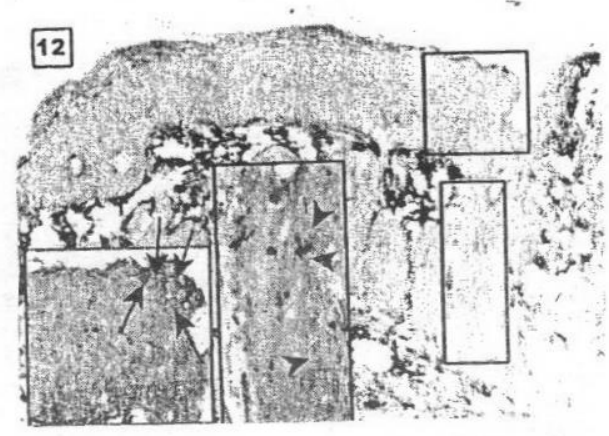

Fig. 12: A photomicrograph of a section of the mice skin 4 days after the injury positive desmoplakin reactivity between the keratinocytes of all layers at the wound margin (arrows in the highly magnified red field), few positive desmoplakin reactivity can be seen in-between the cells of the peripheral part of the neoepidermis (arrow heads in the highly magnified blue field). 11-5F immunoperoxidase stain; X100 \& 400

14

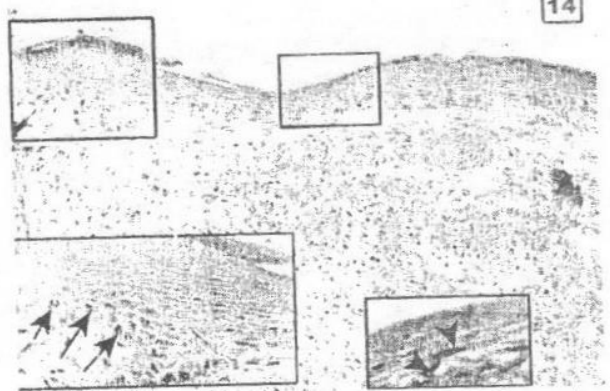

Fig. 14: A photomicrograph a section of the mice skin 6 days after the injury showing showing few PCNA positive cells in the basal layer of the wound margin (arrows in the highly magnified red field), few PCNA positive cells in the basal layer of the floor of the wound (arrow heads in the highly magnified blue fieeld) PCNA immunoperoxidase stain; X100 \& 400 


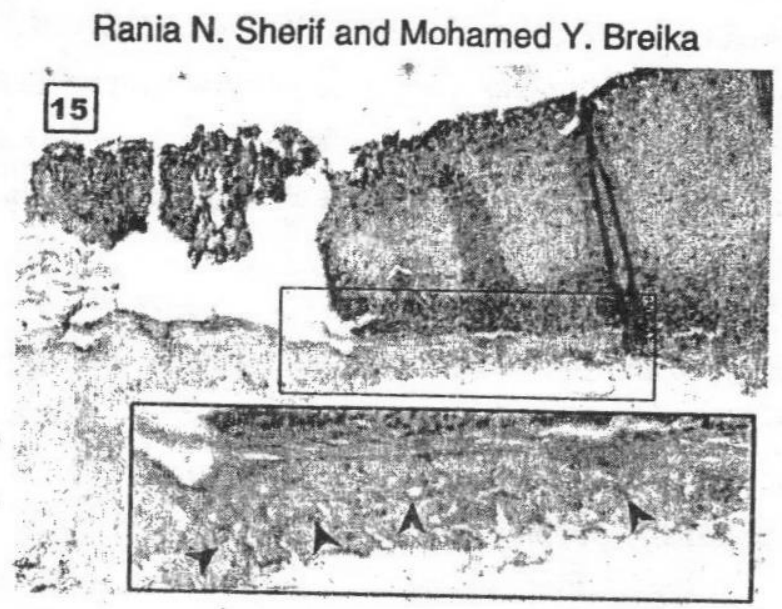

Fig. 15: A photomicrograph of a section of the mice skin 6 days after the injury showing positive desmoplakin reactivity appeared between cells in the floor of the wound (arrow heads in the highly magnified black field). 11-5F immunoperoxidase stain; X100 \& 400

\section{DISCUSSION}

The mechanisms of wound reepithelialization have been debated for a long time but remain unclear. Some studies have described hyperproliferation at the wound margin (Garlick and Taichman, 1994 \& Jansson et al., 1996). Contribution of the cellular proliferation to wound closure remains controversial either negligible (Marks and Nishikawa, 1973 and Pang et al., 1978) or important (Winter, 1972 and Garlick \& Taichman, 1994).

The present study showed that, the cells located at the margin of the wound started to proliferate early during the 1st and 2nd day after injury.
This proliferation was observed mainly in the basal layer and to less extent in the suprabasal layers. It has been previously reported that, breaking the continuity of the epidermal cell layer leads to stimulation of cell division processes in basal epidermal cells (Mcminn, 1969 and Christophers, 1996), by serum factors such as complement proteins, cytokines and growth factors, and by mediators such as serotonin and histamine (Wooseley, 1991, Flad, 1996 and Kekow and Gross, 1996). This proliferation is thought to reflect reprogramming of epidermal keratinocytes to ones dedicated to wound healing (Coulombe, 2003).

MANSOURA MEDICAL JOURNAL 


\section{CUTANEOUS WOUND HEALING: CORRELATION BETWEEN etc..}

Disappearance of desmoplakin expression in-between some cells located at the superficial layers has been observed in the present study. This might indicate dissolution of the desmosomal junctions and movement of the newly formed cells to the superficial layers as they stopped the proliferation and formed the supplement of the migrating epithelial tongue. This was in agreement with the hypothesis about migration of the superficial keratinocytes to close the wound gap suggested by Ortonne et al., (1981). Also, Sun et al. (1991) noticed loss of cell-cell and cell-matrix contacts after wounding and decreased desmoplakin expression in the migrating keratinocytes at the leading edge of the wound (Garrod et al. 2005). However, adhesion remains intact between more distant cells of the epithelium, probably to allow coordinated migration of the tissue (Beaudry et al., 2010).

Early during the process of wound healing, PCNA positive cells were observed among the cells in the floor of the wound which indicated that those cells restored their ability to proliferate after their migration. This in agreement with previous observation that proliferative burst occurs after cell migration (Martin, 1997).

By the $4^{\text {th }}$ day after injury, the proliferation of the cells at the wound margin has been decreased while this of cells at the floor of the wound was still increased. The cells in the floor of the wound might represent the new source of the cells that would cover the whole gap in agreement with Garlick and Taichman (1994) who reported that by the $3^{\text {rd }}$ day the migrating epidermal tongue hyper-proliferates for the maintenance of the migrating cell mass. On the other hand, the desmoplakin expression started to appear in-between cells of the superficial layers of the wound margin, which could be explained by stopping of the migration of those cells in agreement with Garrod et al. (2005) who stated that desmosomal adhesion junctions are initially destabilized at the wound front to facilitate proliferation and migration, and are reassembled later during the sealing of the epithelium.

The current detailed observations along the new epidermis showed that 


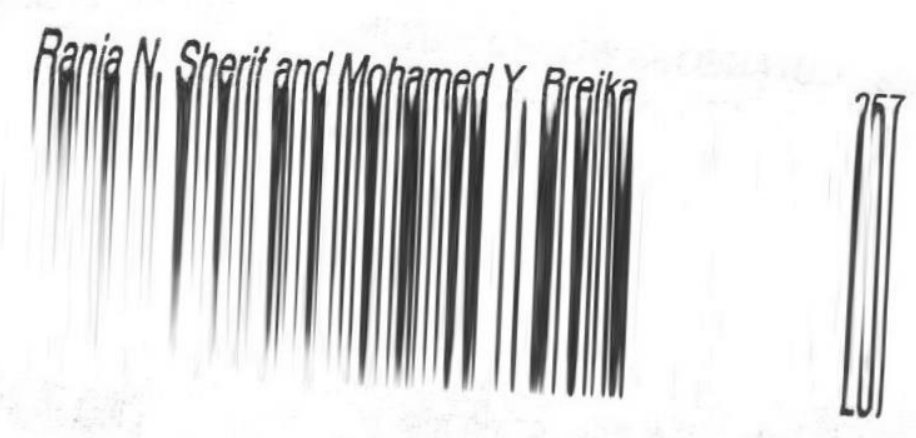

keratinocytes hyperproliterate in the central regions to supply migrating and differentiating cells, after which they normalize their proliferation rate in the peripheral area that had reepi-

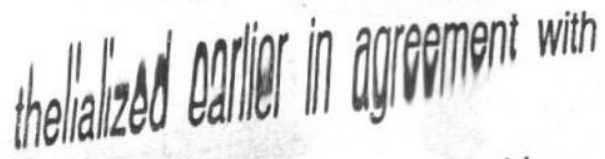

II solante et al., 2001). This could explain the current observamon avous positive desmoplakin reactivity inbetween cells of the peripheral part of the neoepidermis as they will stop migration and start the process of differentiation and provide adhesive strength to the migrating epithelium (Beaudry et al., 2010). However, the desmoplakin reactivity was intracytoplasmic in the cells of the central part of the neoepidermis as those cells will continue the process of proliferation and migration.

By the $6^{\text {th }}$ day, the wound was completely closed. Proliferation of the cells at the wound margin decreased to reach a level below the normal level. This is might be due to inhibition of the process of proliferation and increase in the process of remodeling and apoptosis (Kane and Greenhalgh, 2000).

Minimal proliferation was observed in the floor of the wound. This was expected to increase to the normal level by day 10 to restore the whole epidermis at the floor of the wound according to Beaudry et al. (2010).

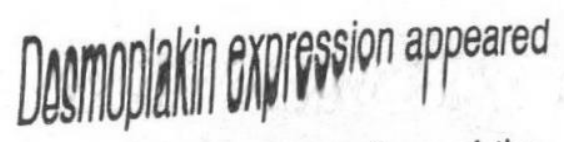
between the cells of the floor of the wound and was oxpected to be increased as Beaudry et al. (2010) reported that by day 10 , expression of all desmosomal components will be restored to levels similar to those observed in uninjured epidermis.

It has been observed that during the process of wound healing the proliferating cells in the hair follicles were markedly increased in number. Those cells might be a source of the cells that would close the wound gap (Sun et al., 1991). Hair follicle epithelial stem cells have been demonstrated to be critical for re-epithelialization during wound healing in mouse skin (Brouard and Barrandon, 2003).

In conclusion, the cells at the wound margin underwent proliferation, pushed toward the surface, lost their desmoplakin expression then they underwent migration to cover the

MANSOURA MEDICAL JOURNAL 
CUTANEOUS WOUND HEALING: CORRELATION BETWEEN EIC..

wound. Later, the new epidermis in

the floor of the wound would form the source of the cells that would cover the wound. The keratinocytes hyperproliferated in the wound floor to sup-

ply the migrating and differentiating cells, after which they normalizo thoir proliferation rate and restore their desmoplakin expression starting from the peripheral area toward the central region. Further studied are needed to elucidate the mechanism of keratinocyte migration and the apoptotic process that occurs during the process of remodeling and the actual role of hair follicles during the process of wound healing.

\section{REFERENCES}

Beaudry, V.G., Ihrie, R.A., Jacobs, S.B.R., Nguyen, B. et al. (2010) : Loss of the Desmosomal Component Perp Impairs Wound Healing In Vivo. Dermatology $R e$ search and Practical. 2010:75973.

Bornslaeger, E.A., Corcoran, C.M., Stappenbeck, T.S. and Green, K.J. (1996) : Breaking the connection: dis- placement of the desmoso. mal plaque protein desmoplakin from celljcell interfaces disrupts anchorage of

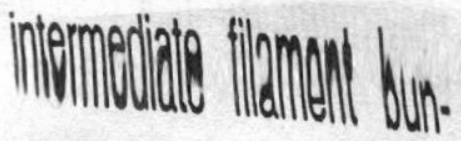

\section{dles and alters intercellular junction assembly. Journal of Cell Biology. 134:985- 1001 .}

Brabo, R. and Macdonald-Brabo, $\mathbf{H}$. (1987) : Existence of two populations of cyclin/ proliferating cell nuclear antigen during the cell cycle: association with DNA replication sites. Journal of Cell Biology. 105, 1549-59 .

Brouard, M. and Barrandon, Y. (2003) : Controlling skin morphogenesis: hope and despair. Current Opinion in Biotechnology. 14, 520 525.

Chidgey, M. (2002) : Desmosomes and disease: an update. Histology and Histopathology. $17,1179-1192$.

Christophers, E. (1996) : Regulatory 
factors in cutaneous wound healing. In Oehmichen, M. and Kirchner, $\mathrm{H}$. (eds): The Wound Healing Process: Forensic Pathological Aspects. Lubeck and SchmidtRomhildn, pp 25-34.

Clark, R.A.F. (1996) : Wound repair overview and general considerations. In: The Molecular and Cellular Biology of Wound Repair (ed. R.A.F. Clark), pp. 3-50, 2nd edn. New York: Plenum Press.

Coulombe, P.A. (2003) : Wound epithelialization: accelerating the pace of discovery. The Journal of Investigative Dermatology. 121(2), 219230.

Flad, H.D. (1996) : Chemokines and proinflammatory cytokines in wound healing. In: Oehmichen, M. and Kirchner, H. (eds): The Wound Healing Process: Forensic Pathological Aspects. Lubeck, Schmidt-Romhild, pp 49-57.
Fukuda, Y., Ito, Y., Azumi, H., Eid, N.A.S. et al., (2002) : Cell death and proliferation in Nd-YAG laser, electrocautery, and scalpel wounds on mice skin. Journal of Dermatological Science 28, 106-118.

Garlick, J.A. and Taichman, L.B. (1994) : Fate of human keratinocytes during reepithelialization in an organotypic culture model. Laboratory Investigation. 70, 916-924 .

Garrod, D.R., Berika, M.Y., Bardsley, W.F., Holmes, D. and Tabernero, L. (2005) : Hyper-adhesion in desmosomes: its regulation in wound healing and possible relationship to cadherin crystal structure. Journal of Cell Science. 118(24), 5743-5754 .

Getsios, S., Huen, A.C. and Green, K.J. (2004) : Working out the strength and flexibility of desmosomes. Nature Reviews. Molecular Cell Biology. 5, 271-81 .

MANSOURA MEDICAL JOURNAL 
CUTANEOUS WOUND HEALING: CORRELATION BETWEEN etc..

Green, K.J., Parry, D.A., Steinert, P.M., Virata, M.L. et al., (1990) : Structure of the human desmoplakins. Implications for function in the desmosomal plaque. The Journal of Biological Chemistry. $265,2603-12$.

Green, K.J., Stappenbeck, T.S., Parry, D. and Virata, M.L. (1992) : Structure of desmoplakin and its association with intermediate filaments. The Journal of Dermatology. 19, 765-9 .

Huen, A.C., Park, J.K., Godsel, L.M., Chen, $X$. et al., (2002) : Intermediate filament-membrane attachments function synergistically with actin-dependent contacts to regulate intercellular adhesive strength, Journal Cell Biology. 159, 1005-1017.

Jansson, K., Kratz, G., and Haegerstrand, A. (1996) : Characterization of a new in vitro model for studies of reepithelialization in human par- tial thickness wounds. In Vitro Cellular and Developmental Biology. Animal. 32, 534-540.

Javierre, E., Vermolen, F.J., Vuik, C. and van der Zwaag, S. (2009) : A mathematical analysis of physiological and morphological aspects of wound closure. Journal of Mathematical Biology. 59, 605-630.

Jonkman, M.F., Pasmooij, A.M., Pasmans, S.G., van den Berg, M.P. et al., (2005) : Loss of desmoplakin tail causes lethal acantholytic epidermolysis bullosa. American Journal of Human Genetics 77, 653-60.

Kane, C.D. and Greenhalgh, D.G. (2000) : Expression and localization of p53 and bcl-2 in healing wounds in diabetic and nondiabetic mice. Wound Repair and Regeneration $8,45-58$.

Kekow, J. and Gross, W.I. (1996) : 
Role of TGF $\beta$ in wound healing. In Oehmichen, M. and Kirchner, $\mathrm{H}$. (eds): The Wound Healing Process: Forensic Pathological Aspects. Lubeck, SchmidtRomhild, pp 59-68 .

\section{Laplante, A.F., Germain, L., Auger,} F.A. and Moulin, V. (2001) : Mechanisms of wound reepithelialization: hints from a tissue-engineered reconstructed skin to longstanding questions. Federation of American Societies for Experimental Biology Journal. 15, 2377- 89.

Li, J, Chen, J. and Kirsner, R. (2007) : Pathophysiology of acute wound healing. Clinics in Dermatology 25, 9918.

Marks, R., and Nishikawa, T. (1973) : Active epidermal movement in human skin in vitro. British Journal of Dermatology. 88, 245-248.

Martin P. (1997) : Wound healingaiming for perfect skin re- generation. Science. 276, 75-81.

Mcminn, R.M.M. (1969) : Tissue repair. New York London, Academic Press.

North, A.J., Bardsley, W.G., Hyam, J., Bornslaeger, E.A. et al., (1999) : Molecular map of the desmosomal plaque. Journal of Cell Science. $112,4325-4336$.

Ortonne, J. P., Loning, T., and Schmitt, D. (1981) : Immunomorphological and ultrastructural aspects of keratinocyte migration in epidermal wound healing. Virchows Archiv. 392, 217 230.

Pang, S. C., Daniels, W. H., and Buck, R. C. (1978) : Epidermal migration during the healing of suction blisters in rat skin: a scanning and transmission electron microscopic study. American Journal of Anatomy. 153, 177-191.

MANSOURA MEDICAL JOURNAL 
262 CUTANEOUS WOUND HEALING: CORRELATION BETWEEN etc. Parrish, E.P., Steart, P.V., Garrod, Tomlinson, A. and Ferguson, M. W.

D.R. and Weller, R.O. (1987) : Antidesmosomal monocional antibody in the diagnosis of intracranial tumours. Journal of Pathology. $153,265-273$.

Singer, A.J. and Clark, R.A. (1999) : Cutaneous wound healing. New England Journal of Medicine. 341, 738-746.

Stenn, K. S., and Malhotra, R. (1992) : Epithelialization. In: Wound Healing, Biochemical \& Clinical Aspects (Cohen, K. I., Diegelmann, R. F. and Lindblad, W. J., eds) pp. 115-127, W. B. Saunders, Philadelphia .

Sun, T.T., Cotsarelis, G. and Lavker, R.M. (1991) : Hair follicular stem cells: the bulge activation hypothesis. Journal of Investigative Dermatology. $96,77 \mathrm{~S}-8 \mathrm{~S}$.
(2003) : Wound healing: a model of dermal wound repair. Methods in Molecular Biology. 225, 249-260.

Vasioukhin, V., Bowers, E., Bauer, C., Degenstein, L. and Fuchs, E. (2001) : Desmoplakin is essential in epidermal sheet formation. Nature Cell Biology. 3, 1076-85 .

Winter, G. D. (1972) : Epidermal regeneration studied in domestic pig. In: Epidermal Wound Healing (Maibach, H. I., and Rovee, D. T., eds) pp. 71-113, Year Book Medical Publishing, Chicago.

Wooseley, J. (1991) : Measuring cell proliferation. Archive of $\mathrm{Pa}$ thology and Laboratory Medicine. 115, 555-557 . 


\title{
الملخص العريى \\ التئام الجروح الجلدية: الارتباط بين ابانة المستضد \\ النووى للخلية المتكاثرة و اللديسموبلاكين
}

\author{
رانيـا نعيـم ثـريـف و مححمـل يـوسـف بـريكـهـ \\ قسم التشريح و الأجنة - كلية الطب - جامعة المنصورة
}

المقدمـة والهـدف من البحث

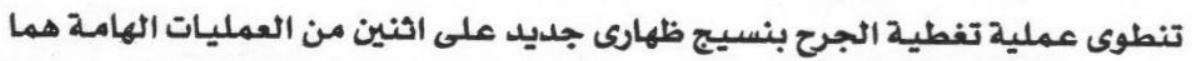

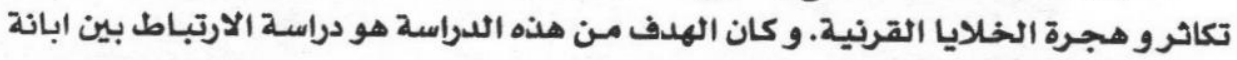

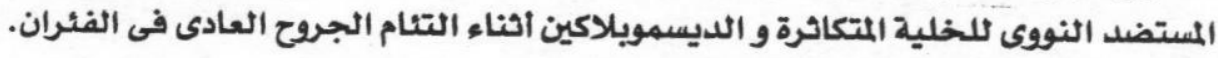

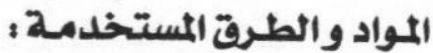

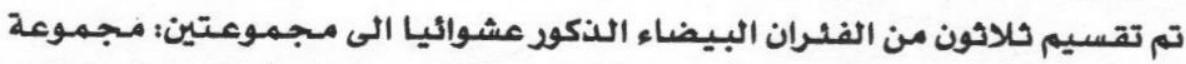

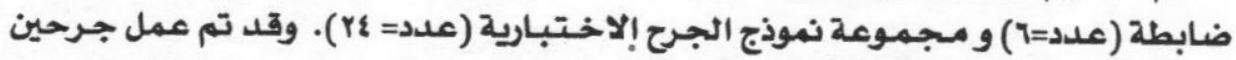

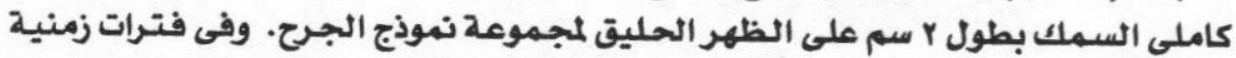

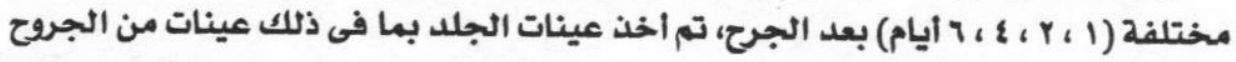

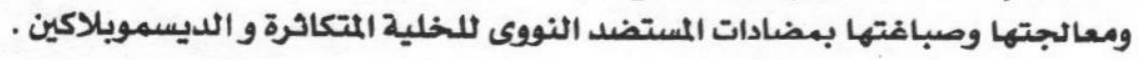

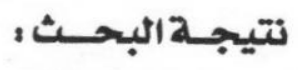

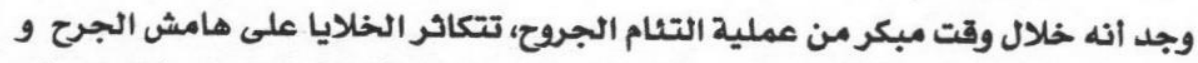

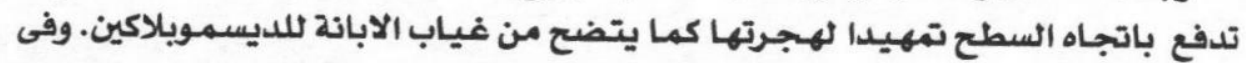

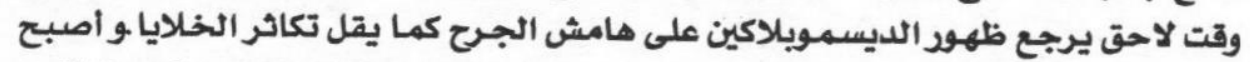

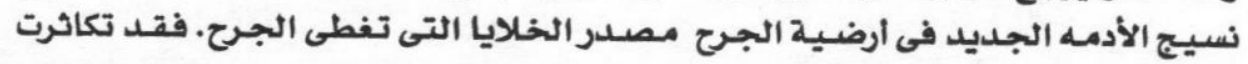

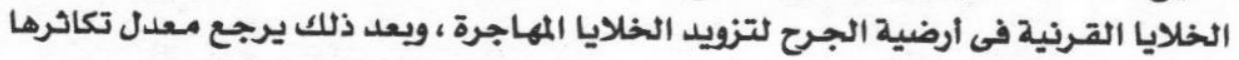

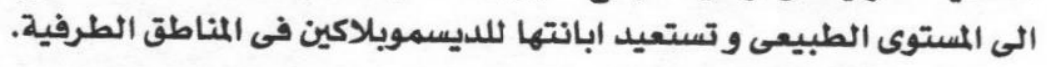

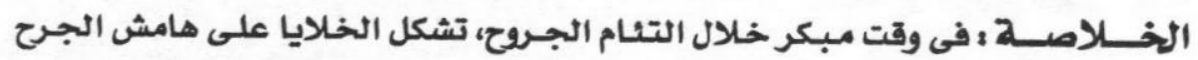

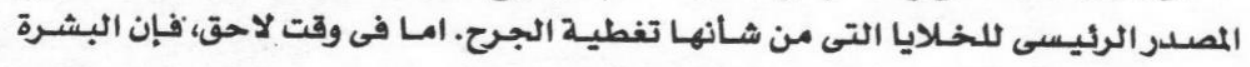
الجديدة فى ارضية الجرح تشكل هذا المصدر.

MANSOURA MEDICAL JOURNAL 
